\title{
Metaphorical Analysis of Discourse on Early Saudi Attempts to Include Women in Unconventional Work Environments
}

\author{
Shrouq Al Maghlouth \\ King Faisal University, Hofuf, 31982, Al Ahsa, Saudi Arabia
}

\begin{abstract}
Objective - This paper examines empirically the discourse on social change as represented in gender-related posts on English blogs written by Saudi bloggers. Slightly more than a decade ago, Saudi women were allowed and encouraged by the government to work in unconventional work environments (outside the fields of education and health care); this stirred controversy across the country.

Methodology/Technique - This analysis is based on an understanding of discourse as both shaping and being shaped by social and cognitive contexts. In so doing, it approaches the data from a socio-cognitive perspective with a focus on the mental models underlying the discursive representations at hand. The adopted methodology is based on metaphor analysis due to the inherently cognitive nature of metaphors. Consequently, an eclectic approach combining insights from conceptual metaphor theory and critical theory analysis is used.

Finding - Data analysis reveals two main findings. First, change is constructed cognitively as challenging and demanding for both women aspiring to work in unconventional professions and their supporters on authoritative and non-authoritative levels. This, however, clashes with the second finding, as in these blogs women are metaphorically constructed in an objectifying and victimizing manner.

Novelty - Such a mismatch calls for a careful examination of some gender constraining cognitive constructions as they are, surprisingly, constructed and reproduced even within discourse attempting to empower women.
\end{abstract}

Type of Paper: Empirical.

JEL Classification: M14, Q56

Keywords: Social Change; Critical Discourse Analysis; Women's Empowerment; Metaphor Analysis

Reference to this paper should be made as follows: Maghlouth, S.A. (2021). Metaphorical Analysis of Discourse on Early Saudi Attempts to Include Women in Unconventional Work Environments, GATR Global J. Bus. Soc. Sci. Review, 9(1): 01 - 09. https://doi.org/10.35609/gjbssr.2021.9.1(1)

\section{Introduction}

In recent years, Saudi women have been empowered on a number of levels that were not readily available to them at the dawn of this century.

\footnotetext{
* Paper Info: Revised: December 10, 2020

Accepted: March 31, 2021

* Corresponding author: Shrouq Al Maghlouth

E-mail: salmaghlouth@kfu.edu.sa

Affiliation: King Faisal University, Hofuf, 31982, Al Ahsa, Saudi Arabia
} 
In the last two decades, social change has been initiated, constructed and distributed discursively in both governmental and non-governmental circles, with the topic of women's inclusion in unconventional work environments provoking controversial positions among the heterogeneous society of Saudi Arabia. Examining such discourse on the Saudi scene inherently falls within the realm of critical discourse analysis (CDA); however, so little research has been devoted to this enterprise that Lacroix (2011, p. 1), for example, refers to these areas as 'terra incognita'. While more attention has been directed toward this direction in the last decade or so, there is still a growing need for more deliberate works targeting the discourse on social change in Saudi Arabia. The current paper offers a CDA on how the diverse positions on these unconventional inclusions- along with men and women as main social actors - have been constructed metaphorically in blog posts written by bloggers presenting themselves as supporters of change and women's empowerment. These posts were written between 2009 and 2011, thus documenting the very early support for and opposition to this topic. The subject of women's empowerment expanded drastically after King Salman - the current Saudi monarch - ascended to the throne in 2015. In fact, many consider this current time to be the golden era for Saudi women. In February 2020, Riyadh, the capital city of Saudi Arabia, was named the Capital of Arab women, which signifies the need for thorough analyses of how women's empowerment is portrayed in discourse.

This paper is based on a doctoral thesis examining the relationship between discourse and social change from a socio-cognitive perspective (Al Maghlouth, 2017). Following this introduction, it consists of five main sections. Section 2 reviews the relevant literature by discussing some key terminology and presenting relevant cases where CDA has been employed. It also offers a concise account of the theoretical foundation underpinning this paper and it establishes the gap motivating this undertaking. Section 3 examines how this foundation can be transformed into a proper methodology for data collection, besides justifying why one linguistic manifestation (i.e., metaphor) is used as evidence for ideological motivations. Section 4 presents a detailed account of the data analysis, which is later discussed in section 5 in light of the previous sections. Finally, it concludes with some suggestions for further research and the limitations of the study.

\section{Literature review}

The current paper originates from a view of discourse as a contextually situated phenomenon, with a dual take on discourse being both constitutive of and constituted by social context (van Dijk, 2011; Wodak \& Meyer, 2009). This multi-faceted and interactive view of discourse and its reciprocal relationship with social practice relates to the Foucauldian notion of discourse (Foucault, 1972). In this perspective, O'Halloran (2003) states, discourse interplays with knowledge as an organized system in a given institution, including the constitution, distribution, transmission, and reproduction of its values.

\subsection{Critical discourse analysis and gendered discourse}

Critical discourse studies, similar to the present one, have the intention of highlighting areas of power inequality. Fairclough, Mulderring and Wodak (2011, p. 358) suggest that such an enterprise should be approached as a 'committed' science interfering with social practice rather than being 'dispassionate' and 'objective'. By the same token, Gee (2014) distinguishes between descriptive discourse studies on the one hand and critical ones on the other. In the first, the analyst is concerned with describing language primarily in order to understand it, not to take action based upon this description. In contrast to this, the critical vein in discursive studies obliges the analyst to take a stance. This commitment takes on a special significance when coupled with research on gendered discourse (van Dijk, 2015; Lazar, 2005).

Lazar and Kramarae (2011, p. 224), for instance, discuss the many stereotypical perceptions of women around the globe as they are 'bunched together' in the same jobs, earning less than men, struggling to obtain leadership positions and yet caring for their own families. While variations of these scenarios are evidently present, cases of discriminating discourse are still manifested in most societies. In a study by Al-Hejin 
(2015), a CDA examination was conducted to analyse the sematic macrostructures in the BBC coverage associated with Muslim women. His findings reveal a negative stereotypical conception of women in hijab, i.e., a head veil/scarf. These representations portrayed the hijab as 'imposed', thus confirming the degrading conceptions of Muslim women as 'passive, submissive and unwilling or unable to improve their own wellbeing' (Al-Hejin, 2015, p. 40).

In a recent study by Altohami and Salama (2019), the journalistic representations of Saudi women in a corpus of contemporary English were critically analyzed. Similar to Al Hijen's findings, Altohami and Salama report negative stereotypical representations associated with Saudi women in the American media between 1990 and 2018. The victimization of women was among the most effective discursive strategies employed within this corpus. Stereotyping was another strategy where women were again portrayed as 'submissive, oppressive and covered in black' (ibid, p. 333). By the same token, all efforts made by decision makers in Saudi Arabia toward women's empowerment are expressed through the strategy of normalization, where they are rendered superficial and insignificant.

Both of the studies examined in the last two paragraphs report negative stereotypical representations of Saudi women and/or social change empowering this particular group within Western media portrayals. It is intriguing that Al Hijen (2012) published relatively similar findings even though the stereotypes were depicted in local rather than national media. This highlights the need for thorough analyses of such discourses in order to ensure a more just power distribution within them (see discussion on the democratization of discourse in section 2.2). There appears to be a disturbing clash between the intentions motivating these discourses on the one hand and how they are actually portrayed in reality. For instance, Al Maghlouth (2018) reveals inconsistencies in how intertextuality and recontextualizations, as linguistic tools, are portraying this clash within the same discourse. Intertextuality examines the links created between one text and other references or texts, be it here and now or in the distant past or future (Reisigl and Wodak, 2009). While the posts under study were claiming to promote social change discursively, they failed to address it appropriately as they were creating very closed communities in which they were preaching to the 'already converted' (Al Maghlouth, 2018: 196).

Another fundamental aspect that merits attention is the fact that the discourse under question in this paper can be classified as an example of positive discourse (Martin, 2004). In this vein, the analyst attempts 'CDA irrealis' which is rather directed toward 'constructive social action' (ibid, p. 182). Since the posts targeted in this paper are supportive of social change and women's empowerment, it is even more critical to screen them occasionally to eradicate any instances of clashes or inconsistencies in the representations of the social actors involved or the construction of change in general. Along the same line, the positive streak within this take on discourse analysis should not be seen as being opposite to CDA but rather a 'variant' (Chojnicka, 2015, p. 225).

\subsection{Multiplicity of theory and application in CDA}

CDA seems to be suited to uncovering the representations demonstrated by the blog posts under study, but one should keep in mind that there is a multiplicity of theoretical motivations fueling these analyses that corresponds to the multidisciplinary nature of CDA. For instance, the discourse historical approach (Reisigl \& Wodak, 2009), the social actor approach (van Leeuwen, 1996,), and the socio-cognitive approach (van Dijk, 2009) have been quite popular among analysts since they address discourse operationally as a 'recontextualization of social practice' (van Leeuwen, 2009, p. 148). The first two approach discourse inductively and thus appear to be more specific and problem oriented (Tenorio, 2011). Therefore, they can be best employed within broader schematic approaches (Al Maghlouth, 2017). The socio-cognitive approach, on the contrary, is more deductive and centers on the discourse-cognition-society triangle (van Dijk, 2009, p. 64). Drawing on the theory of social representations (Moscovici, 2000), van Dijk proposes the notion of 
context mental models, which have the responsibility of 'controlling discourse processing and adapting discourse to the social environment so that it is situationally appropriate' (2009, p. 65).

Bearing in mind the aforementioned social changes taking place on the Saudi scene, an investigation of mental models as cognitive constructs lends itself readily to the current theoretical basis upon which this paper is founded. To illustrate, within most discourses promoting and calling for social change, rejection of inequality is pushed forward through what Fairclough (1992, p. 201) refers to as the 'democratization' of discourse, a process in which power asymmetries are removed from the linguistic and discursive constructions of people or groups. Here emerges the notion of 'competing ideologies' (van Dijk, 1998, p. 138), where two ideological forces operate simultaneously within a given society, shaping and being shaped by discursive practices. What constitutes these forces, however, is factors that extend beyond the immediate discursive context and could consequently be political, historical, cultural, or social (Wetherell, 1998, 2001a). None of these ideologies are expected to, or are able to, accomplish utter supremacy (Auguostinous et al., 2006). Hence, it is to be expected that some might be more stable and fixed across different times and places, which highlights the vital role assumed by discourse in bringing about desired social change.

Before concluding this literature review, it is of key relevance to stress that the aforementioned ideological discussion is more of an abstraction with diverse indirect traces in reality. As a result, the first section of the methodology explores how to link such theorization to actual practice, i.e., language in use.

\section{Research methodology}

The inherent multiplicity and multi-disciplinarity in CDA are inevitably mirrored by a breadth and diversity of methodology. This, coupled with the socio-cognitive approach adopted in this paper, requires a multi-level analysis, which has always been 'the norm' in CDA (Al Maghlouth, 2017). This has been established since the early days of CDA with the perception that discourse communicates '(i) social identities, (ii) social relations and (iii) systems of knowledge and beliefs' (Fairclough, 1993, p. 134-5). These align with the long-established three metafunctions of language: the ideational metafunction denoting ideas, entities and people; the interpersonal metafunction identifying interpersonal relationships between interlocutors; and, on the surface, the textual metafunction examining cohesion and coherence (Halliday, 1978).

In accordance with this, the paper at hand attempts a threefold analysis examining the textual, discursive, and socio-cognitive levels of discourse. While numerous methods could be used in such analyses, metaphor analysis is inherently cognitive and has deep connections with the socio-cognitive approach (Al Maghlouth, 2017). A lay person might think of metaphors as belonging exclusively to literary works and pure imagination. However, metaphors have recently been widely acknowledged as linguistic and textual tools of everyday language (Cameron, 2003). Therefore, it is no wonder that an increasing amount of research is directed toward decoding metaphors in a diversity of discourses; see for instance Stibbe (2013) and Musolff (2007). The driving force behind these works is examining the potential of such cognitive constructs for constituting social context. Ezeifeka (2013) links this to the Whorfian determinism theory on how language is affecting our perceptions of the world. Therefore, an eclectic approach to metaphor analysis combining insights from conceptual metaphor theory and critical metaphor analysis has been adopted in this paper.

Conceptual metaphor analysis was first established by the work of Lakoff and Johnson in their book, Metaphor we live by. In that sense, Semino (2008, p. 5) states that a conceptual metaphor is viewed as 'mappings' where a 'target' domain is constructed in the light of another 'source' domain. The problem, however, is that the conceptual metaphor theory runs the risk of overlooking how this mapping operates pragmatically. Ezeifeka (2013), for instance, believes that it is insufficient to grasp the potential of metaphors in ideological discourses attempting to project beliefs or to win over crowds. Therefore, it is necessary to combine it with another methodological framework: critical metaphor analysis. Set forth by Charteris-Black (2004, p. 21), this method targets the identification, interpretation, and explanation of metaphors as used in discursive practices on linguistic, cognitive, and pragmatic levels. 
The posts under examination were collected from four Saudi blogs that were popular at the time when the reformative decision to include women in unconventional work environments was taken. This was between 2009 and 2012, when change was brought in subtly with the aid of the government amid social and ideological controversy. This period was prior to the shift from this type of blogging in Saudi Arabia to microblogging (i.e., Twitter). These blogs were written in English by Saudi bloggers, native speakers of Arabic, who represented themselves as supporters of women's empowerment against opponents who often belonged to a more conservative/traditional stream. Each post was assigned a number and then transcribed using a clause-based transcription system inspired by Halliday and Mattiessen's (2014) systemic functional grammar. For the sake of clarity of presentation, the examined metaphors are grouped in clusters thematically and are first analyzed descriptively and then interpreted cognitively and pragmatically.

\section{Results}

Following the aforementioned analytical framework, all of the metaphoric expressions in the posts were identified, analyzed, and checked for any recurring patterns. Four metaphorical clusters can be pinned down as follows.

\subsection{First cluster: movements}

This cluster is one of the most common clusters identified in the analysis. It originally borrows images from the source domain of physical movement to account for the target domain of change. This is a case of reification, which takes place when semantic tension is created by using an expression outside its original meaning, to convey a shift from the abstract to the concrete. This could be exemplified as follows:

It would be a shame if another door closes in the faces of women who are in desperate need of jobs. (post $19,42-43)$

Financial gain in the form of student stipends and later employment salaries has gotten women over the mountain of family consent to study and then teach. (post 21,31)

then there is little use to make our precious jewels/diamonds work in dead end jobs all while being driven around like queens. (post 24,6)

Saudi Women Lawyers: Equal Footing? (post 26, 1)

Within this perspective, the proposed unconventional professions under examination are portrayed as a desired destination, requiring movement on the part of both women and their supporters. Therefore, a more general conceptual metaphor is presented here, CHANGE IS MOVEMENT, with two relevant, yet more specific metaphors. The first of these is CAREER IS A ROAD, with obstacles impeding women from proceeding in this journey, as in a and b. Along the same lines, the underlined metaphor in c portrays nonaspirational jobs as a dead-end road. Second, CAREER IS A RACE is evident in d, which entails equality in allowing both genders equal opportunities within the legal field.

\subsection{Second cluster: physical encounter}

The second cluster also uses reification by borrowing images from the source domain of physical encounter to account for how both change and resistance to change are portrayed. Below are six examples demonstrating this:

a. The proposal was made by Jeddah Chamber of Commerce, who said they will keep pushing this proposal over the next three years. (post 28,4)

b. And I'm glad to say that these women are fighting back with a lawsuit against the website. A lawsuit that the ladies are highly likely to win. (post 21, 27-28)

c. Small cracks began to open in the system as the word spread. (post 26, 13-14) 
d. You'll break one of our main contradictions regarding interaction between men and women. (post 20,8)

e. Describing yesterday's meeting, al-Hayat said Fakieh had to face a "heated verbal pelting" by the clerics. (post 27, 24)

f. and had to face similar opposition from conservatives over women employment. (post 27,8)

The source domain visited here works in two opposing ways. In the first one, as in e and f, physical action is taken against opponents of these reformative inclusive measures. Hence, SUPPORT IS PHYSICAL ACTION could be inferred to account for all the action taken by supporters of women's empowerment, be it on a higher executive level or as individual measures taken by these women themselves. This action ranges from relatively subtle, as in pushing in e, to fighting back in $\mathrm{f}$, which denotes a much stronger action. Relevant to this, a sub-metaphor could be inferred from $\mathrm{g}$ and $\mathrm{h}$ where the desired change is portrayed as breaking the status quo, thus denoting CHANGE IS A CRACK as a conceptual metaphor. On the other hand, in $\mathrm{i}$ and $\mathrm{j}$, the action is taken on the part of the opponents who, similarly, range from mere opposition in $\mathrm{j}$ to violent pelting in i. Hence, DISAGREEMENT IS PHYSICAL ACTION could be a parallel to the support and agreement in the first conceptual metaphor in this cluster.

\subsection{Third cluster: Nature}

The third cluster objectifies women and men as social actors involved within the same social practice. To illustrate, depersonification is evident when images from the source domain of nature are adopted to portray how the two genders are constructed by both supporters and opponents of change.

a. then there is little use to make our precious jewels/diamonds work in dead end jobs all while being driven around like queens. (post 24,6)

b. "It doesn't make sense to continue viewing men in our society as wolves that look for women in every place," she added. (post 28,7)

c. All the while, Saudi women wilt at home waiting for the government to employ them in jobs that are proper for them to take. (post 21,20)

Example $\mathrm{k}$ demonstrates a case where women are viewed as jewels, being extremely valuable yet vulnerable, meaning that they should be kept safe from any danger. Further depersonification is evident in 1 , where men are portrayed as wolves, predators following their own instinct, thus, in parallel, portraying women as powerless victims chased by such predators. Hence, WOMEN ARE JEWELS and MEN ARE WOLVES are established as two relevant conceptual metaphors. It should be noted, however, that this should be examined in light of the negation found in 1 (section 5). Along the same lines, women in $\mathrm{m}$ are constructed as wilting flowers, thus leading to a relevant conceptual metaphor: WOMEN ARE FLOWERS.

\subsection{Fourth cluster: clean cloth}

The last cluster employs reification to represent personal and social reputation as a clean, presumably white, piece of cloth that should be kept fresh and crisp. In both $\mathrm{n}$ and o below, it is possible to conceive a conceptual metaphor, HONOR IS A CLEAN CLOTH, to highlight the centrality of reputation with this particular context. To illustrate, honor is fragile and vulnerable, and it should be kept away from these tarnishing attempts, which are often associated with calls for change.

a. they are very likely to have our society drag their reputation and that of their families in the mud. (post 2, 22)

b. because our courts tend to bring the hammer down hard when it comes to making outright false allegations that tarnish family honour (post 21, 29-30)

These four clusters have been identified and analyzed descriptively in order to pinpoint their pragmatic and cognitive underpinning and to examine how all of them could be influential at the higher discursive and 
socio-cognitive levels, extending beyond the textual ones. The following section is a discussion of these findings and their implications.

\section{Discussion}

The descriptive analysis above presents some evidence on the mental models associated with change, status quo, and men and women as the two main social actors involved. To begin with, it is evident from the posts that change is associated with some cognitive conceptions by these bloggers, since it is constructed as demanding and requiring a lot of effort. This is true not only for the women who aspire to be empowered as part of these reformative measures, but also for the supporters of this change, regardless of their level of authority. This construction could be linked to mental models supporting change, as opposed to those calling for the preservation of the status quo. It has been argued that mental models that resist status quo and promote change tend to be individualistic and more dynamic, while those that maintain status quo are often more fixed and socially shared (Al Maghlouth, 2017). Over time, those that appeared idiosyncratic and peculiar at first gradually win social acceptance and transform the resistance to change into gradual acceptance.

This discussion can be linked to the metaphoric constructions associated with support for change, as well as its detractors. In both cases, all of the identified cases document constructing acts of support as hard and even challenging. What complicates things even more is the construction of opposition to change as a battle with violent encounters, including wins and losses. All this again links to mental models; as much as people desire change, they also perceive it as a thorny and intimidating task. Such hardship, for instance, derives from the cultural tools employed by opponents of change to attack women, as in the case of the metaphoric expressions associated with honor and reputation, a culturally sensitive theme in Middle Eastern societies.

Such conceptions, however, appear to clash with the images assigned to men and women on these posts. To illustrate, it is quite common to see dehumanizing portrayals of men as predators within change-opposing discourse, within which this technique is employed by conservatives to legitimize their objectifying perception of women. For this perception to be reproduced again in change-promoting discourse might not help this cause, even if it is for the purpose of negating it. This is also intensified by the objectifying images constructing women in such posts. Women, even when hailed for crossing impeding cultural barriers, are still portrayed with victimizing and passive images. Unfortunately, within digital discourses, the reproduction of these constructions takes a different path from within traditional communication. The hyperlinked nature of these blogs allows for intertextuality within texts to expand beyond their normal scope, tremendously affecting their readership and distribution at a discursive level (Al Maghlouth, 2018).

\section{Conclusion}

The textual and discursive analyses of these clusters reveal two major findings, expressed in the language of bloggers who support women in their attempts to engage in unconventional work environments. Evidently the first of these is that change is perceived cognitively as challenging and demanding; thus, it requires a lot of effort on the part of women. However, the second finding demonstrates a somewhat weaker cognitive perception of women in which they are objectified, marginalized, and presented as fragile. This mismatch should be addressed consciously and deliberately in business-related discourse in order to eradicate these constructions and accommodate gender-inclusive work environments. In particular, it is important to promote from the start how the discourse on communication in business can be fabricated in a way that highlights such inconsistencies. For instance, Darics and Koller (2019) argue for a continuous revision of business communication curricula in order to promote adequate language awareness and to equip its learners with proper discourse analysis tools. Here emerges the key significance of interdisciplinary research - linking the fields of discourse and linguistics on the one hand to business-related fields on the other. In addition to this, 
since these posts document an earlier stage of women's empowerment in Saudi Arabia, they provide useful insights for current comparative studies on more recent stages of this movement. Women in Saudi Arabia are now breaking the glass ceiling in both governmental and non-governmental domains. It would be intriguing to find out whether the inconsistencies highlighted in this study still persist in such domains. Finally, it is important to draw attention to certain limitations in this study. First, the fact that these bloggers decided to write in English, which is not their native tongue or the official language of Saudi Arabia, inevitably limits their accessibility to a certain type of audience and thus affects their readership. It should also be pointed out that since the study examines opposing discourse reported within a more pro-change discourse, it runs the risk of subjectivity.

\section{Acknowledgment}

The researcher would like to express her deep gratitude to the Saudi Ministry of Education and King Faisal University for generously funding this study. ORCID ID https://orcid.org/0000-0001-6654-7584

\section{References}

Al-Hejin, B. (2012). Covering Muslim women: A corpus-based critical discourse analysis of the BBC and Arab News (Doctoral dissertation, Lancaster University).

Al-Hejin, B. (2015). Covering Muslim women: Semantic macrostructures in BBC news. Discourse \& Communication, 9(1), 19-46. https://doi.org/10.1177/1750481314555262

Al Maghlouth, S. (2017). A critical discourse analysis of social change in women-related posts on Saudi Englishlanguage blogs posted between 2009 and 2012 (Doctoral dissertation, Lancaster University). https://doi.org/10.17635/lancaster/thesis/145

Al Maghlouth, S. (2018, August). Virtual Communities and Social Change: Intertextuality in Saudi English-language blogs. In Proceedings of the 10th International RAIS Conference on Social Sciences and Humanities (pp. 192-196). Scientia Moralitas Research Institute.

Altohami, W. M., \& Salama, A. H. (2019). The Journalistic Representations of Saudi Women in the Corpus of Contemporary American English (COCA): A Corpus Critical Discourse Analysis. International Journal of English Linguistics, 9(6). https://doi.org/10.5539/ijel.v9n6p320

Augoustinos, M., Walker, I., \& Donaghue, N. (2014). Social cognition: An integrated introduction. Sage.

Cameron, L. (2003). Metaphor in educational discourse. A\&C Black.

Charteris-Black, J. (2004). Corpus Approaches to Critical Metaphor Analysis Palgrave Macmillan. https://doi. org/10.1057/9780230000612

Chojnicka, J. (2015). Contesting Hegemonic Gender and Sexuality Discourses on the Web: Latvian and Polish Discourses of Gender Dissidents. Critical Approaches to Discourse Analysis across Disciplines, 7(2).

Darics, E., \& Koller, V. (2019). Social actors "to go": An analytical toolkit to explore agency in business discourse and communication. Business and Professional Communication Quarterly, 82(2), 214238.https://doi.org/10.1177/2329490619828367

Ezeifeka, C. R. (2013). Strategic use of metaphor in Nigerian newspaper reports: A critical perspective. Critical Approaches to Discourse Analysis across Disciplines, 6(2), 174-192.

Fairclough, N. (1992). Discourse and social change (Vol. 10). Cambridge: Polity press. DOI:10.2307/2074659

Fairclough, N. (1993). Critical discourse analysis and the marketization of public discourse: The universities. Discourse \& society, 4(2), 133-168. https://doi.org/10.1177/0957926593004002002

Fairclough, N., \& Wodak, R. (1997). Critical discourse analysis. Discourse as social interaction, 2, 258-284.

Gee, J. P. (2014). An introduction to discourse analysis: Theory and method. Routledge.

Halliday, M. A. K. (1978). Language as social semiotic: The social interpretation of language and meaning. Hodder Education.

Halliday, M., Matthiessen, C. M., \& Matthiessen, C. (2014). An introduction to functional grammar. Routledge.

Lacroix, S. (2011). Awakening Islam. Harvard University Press. 
Lazar, M. M. (2005). Politicizing gender in discourse: Feminist critical discourse analysis as political perspective and praxis. In Feminist critical discourse analysis (pp. 1-28). Palgrave Macmillan, London. https://doi.org/10.1057/9780230599901_1

Lazar, M. M., \& Kramarae, C. (2011). Gender and power in discourse. Discourse studies: A multidisciplinary introduction, 217.

Martin, J. R. (2004). Positive discourse analysis: Solidarity and change. Revista canaria de estudios ingleses, 49(1), 179-202. DOI: $10.1177 / 0959354306067443$

Musolff, A., Hart, C., \& Lukes, D. (2007). Is there such a thing as discourse history? The case of metaphor. Cognitive linguistics in critical discourse analysis: Application and theory, 1-27.

O'halloran, K. (2003). Critical discourse analysis and language cognition. Edinburgh University Press.

Reisigl, M., \& Wodak, R. (2016). The discourse-historical approach (DHA). Methods of critical discourse studies, 3, 23-61.

Semino, E. (2008). Metaphor in discourse (p. 81). Cambridge: Cambridge University Press.

Stibbe, A. (2013). The corporation as person and psychopath: Multimodal metaphor, rhetoric and resistance. CADADD Journal, 6(2).

Tenorio, E. H. (2011). Critical discourse analysis, an overview. Nordic journal of English studies, 10(1), 183-210.

Van Dijk, T. A. (1998). Ideology: A multidisciplinary approach. Sage. http://dx.doi.org/10.4135/9781446217856

Van Dijk, T. A. (2009). Critical discourse studies: A sociocognitive approach. Methods of critical discourse analysis, 2(1), 62-86. https://doi.org/10.1075/z.184.79dij

van Dijk, T. A. (2011). Introduction: The study of discourse. In T. A. van Dijk (Ed.), Discourse studies: A multidisciplinary introduction (2nd ed., pp. 1-7). SAGE Publications. http://dx.doi.org/10.4135/9781446289068

Van Dijk, T. A. (2015). 22 Critical Discourse Analysis. Discourse analysis, 466. DOI:10.1002/9781118584194

Van Leeuwen, T. (1996). The representation of social actors. Texts and practices: Readings in critical discourse analysis, 1, 32-70. https://doi.org/10.1177/0957926595006001005

Van Leeuwen, T. (2009). Discourse as the recontextualization of social practice: A guide. Methods of critical discourse analysis, 2, 144-161. DOI: 10.1093/acprof:oso/9780195323306.001.0001

Wetherell, M. (1998). Positioning and interpretative repertoires: Conversation analysis and post-structuralism in dialogue. Discourse \& society, 9(3), 387-412. https://doi.org/10.1177/0957926598009003005

Wetherell, M. (2001). Debates in discourse research. Discourse theory and practice: A reader, 380-399.

SAGE Publications. Wodak, R., \& Meyer, M. (2009). Critical discourse analysis: History, agenda, theory and methodology. Methods of critical discourse analysis, 2, 1-33. http://dx.doi.org/10.4135/9780857028020 